ORIENTAL JOURNAL OF
ISSN: 0974-6471
March 2017,
COMPUTER SCIENCE \& TECHNOLOGY

\title{
Virtual Reality Treatments for Specific Phobias: A Review
}

\author{
SUMIT ROY and R KAVITHA \\ Department of Computer Science Christ University, Bengaluru, India. \\ ${ }^{*}$ Corresponding author E-mail: sumit.roy@ mca.christuniversity.in \\ http://dx.doi.org/10.13005/ojcst/10.01.18
}

(Received: March 02, 2017; Accepted: March 09, 2017)

\begin{abstract}
Virtual reality is becoming one of the seamless technology which can be used to treat several psychological problems such as anxiety disorders. With the advancement of technology virtual reality is becoming available to ordinary practitioners to carry out non-clinical therapies. An effective virtual reality system provides the user with total immersion and becomes a part of the virtual world. This study provides an insight as how virtual reality could provide means to overpower anxiety disorders through a controlled environment which is being projected to participants suffering from specific phobias.
\end{abstract}

Keywords: Acrophobia, Claustrophobia, Arachnophobia, Novint Falcon.

\section{INTRODUCTION}

Virtual Reality provides a level of machine and human interaction in which the users become a part of the three-dimensional virtual world. These virtual worlds provide a means of total immersion thus providing a sense of presence for the participant which provides a great leap in comparison to the traditional computer graphics. The participant is subjected to a computer-designed view of a three-dimensional immersive virtual world that changes in a natural way per the head and body motion. For some virtual environments, the participant can also hold a second position input sensor in their hand that allows them to manipulate a virtual hand to interact with the environment, for example, push an elevator button and ascend.
Thus, virtual reality is a revolutionary technology that provides a virtual environment or virtual world which combines different sensory input devices, body tracking devices and real time graphics. The sense of presence is accomplished by combination of various input and computer display technologies capable of showcasing various static and dynamic objects.

\section{Treatment For Phobia}

For the treatment of specific phobias, a sense of presence becomes necessary while operating exposure therapy. Though traditional exposure therapy methods provided a sense of presence, the therapy sometimes did not accumulate proper results. For example, during the exposure in vivo the participants often feel uncertain 
before projecting themselves to the environment. Thus, bringing down the overall success of the experiments.

\section{Exposure in VIVO}

The usage of vivo therapy is popular and well-established method for the treatment of psychological disorders such as phobias. Many psychotherapy sessions involve exposure to fear provoking situations for the treatment of anxiety disorders and has been clinically proved to be immensely effective for the treatment ofphobic, and anxiety disorders. Treatment activities during the vivo exposure include the participant to be taken to locations such as going close to the edge of a building and looking down at the ground level which elicit the fear of the specific phobia as highlighted by the participant. During each

Table 1: Overview of Specific Phobias

\begin{tabular}{|c|c|c|c|}
\hline Name & Description & Treatment & Questionnaire \\
\hline $\begin{array}{l}\text { Acrophobia } \\
\text { (Fear of } \\
\text { Heights) }\end{array}$ & $\begin{array}{l}\text { Acrophobia can be } \\
\text { termed as extreme } \\
\text { or irrational fear of } \\
\text { heights and comes } \\
\text { under the category } \\
\text { of specific phobias } \\
\text { called motion and } \\
\text { space discomfort. }\end{array}$ & $\begin{array}{l}\text { Subjects are } \\
\text { projected } \\
\text { to heigh } \\
\text { t phobic } \\
\text { scenarios. }\end{array}$ & $\begin{array}{l}\text { Questionnaire for } \\
\text { the measuring of } \\
\text { the } \\
\text { sociodemographic } \\
\text { data, The } \\
\text { Acrophobia } \\
\text { Questionnaire. }\end{array}$ \\
\hline $\begin{array}{l}\text { Claustrophobia } \\
\text { (Fear of } \\
\text { Confined } \\
\text { Spaces) }\end{array}$ & $\begin{array}{l}\text { Claustrophobia is } \\
\text { typically the fear } \\
\text { of confined spaces } \\
\text { and can be as } \\
\text { classified as an } \\
\text { anxiety disorder } \\
\text { which can result } \\
\text { in panic attacks. }\end{array}$ & $\begin{array}{l}\text { Different } \\
\text { stages with } \\
\text { each stage } \\
\text { having a } \\
\text { more } \\
\text { difficult } \\
\text { virtual } \\
\text { scenario. }\end{array}$ & $\begin{array}{l}\text { The } \\
\text { Claustrophobia } \\
\text { Questionnaire, } \\
\text { Anxiety } \\
\text { Sensitivity Index } \\
\text { (ASI). }\end{array}$ \\
\hline $\begin{array}{l}\text { Arachnophobia } \\
\text { (Fear of } \\
\text { Spiders) }\end{array}$ & $\begin{array}{l}\text { Arachnophobia is } \\
\text { a specific phobia } \\
\text { which is characte- } \\
\text { rized by fear of } \\
\text { spiders. }\end{array}$ & $\begin{array}{l}\text { Involve a } \\
\text { haptic } \\
\text { feedback } \\
\text { device such } \\
\text { as the } \\
\text { Novint } \\
\text { Falcon. }\end{array}$ & $\begin{array}{l}\text { Fear of Spider } \\
\text { Questionnaire. }\end{array}$ \\
\hline $\begin{array}{l}\text { Flying Phobia } \\
\text { (Fear of } \\
\text { Flying) }\end{array}$ & $\begin{array}{l}\text { An individual } \\
\text { suffering from } \\
\text { flying phobia go } \\
\text { through several } \\
\text { repercussions } \\
\text { which include } \\
\text { social } \\
\text { embarrassment } \\
\text { such as not being } \\
\text { able to go to } \\
\text { airport, boarding a } \\
\text { flight etc. }\end{array}$ & $\begin{array}{l}\text { Involves } \\
\text { virtual } \\
\text { plane and } \\
\text { other } \\
\text { aspects of } \\
\text { boarding a } \\
\text { flight such } \\
\text { as altering } \\
\text { weather } \\
\text { conditions. }\end{array}$ & $\begin{array}{l}\text { The Fear of Flying } \\
\text { Inventory, SUDS } \\
\text { (Subjective Units } \\
\text { of Discomfort } \\
\text { Scale) }\end{array}$ \\
\hline
\end{tabular}


of the sessions, the anxiety level of the patients was obtained at regular intervals through a 0-8 scale (SUDS). When the fear or anxiety tends to diminish, the therapist encourages the patient to do a more immense exercise. During the therapy, the patients were asked not to participant themselves to any exposure exercises outside the sessions. Though theparticipant's exposure to a situation or a feared object can be altered from gradual to flooding depending upon the participant's stimulus reaction or comfort, this exposure therapy has several disadvantages. The sessions cannot be conducted in the therapist office and are to be conducted in real environment. Although the therapist accompanies the participant, the therapist has no control over the environment. For example, if a participant is suffering from fear of flying, the patient can be taken to a real airplane to evoke fear stimuli but the other elements which is related to the session such as weather or a smooth takeoff by the flight cannot be guaranteed. Even though the participant is projected to a real-time situation there is no guaranty that the exposure will be dealt with confidence by the participant, as the participant might have a feeling of public embarrassment. Furthermore, the participants can back out during the sessions if the participant found the scenario to be risky and a possess a threat to their life.

\section{Imagino Therapy}

Imagino therapy is another form of exposure therapy which is used for specific phobias. In this process the participant or the participant is made to imagine scenarios which rise their anxiety level and provoke stimuli. This is basically a clinical therapy which is accompanied with a psychotherapist. The psychotherapist continuously interacts with the participant undergoing therapy and tries to encourage them. The patient is asked to relate to incidents which might have had happened earlier in his/her life which have created a serious anxiety issue for the participant. People suffering from a particular phobia also experience nausea, excessive sweating, breathlessness, and the inability to speak or think clearly during the sessions. The therapist tries to relate the participant to his/her imagination so such a level where the participant is fully engrossed and goes through the same fear which he/she has witnessed before. These sessions can go on until the therapist feels the participant feels uncomfortable and is not able to cope up with the stress. It is cost effective as it does not require a hardware or software infrastructure to set it up. This process though is not much effective and has gained less popularity as the patient is asked to imagine everything. Unlike vivo exposure or VRET this doesn't implement any practical approach.

\section{Virtual Reality Exposure Therapy (VRET)}

Virtual Reality exposure therapy also known as virtual reality therapy incorporates recent technology in virtual reality to treat patients suffering from specific phobias and post-traumatic stress. Presently, the advancement of display and computer technology allows evolving of stimuli resembling to real world phobic situation through virtual environments ${ }^{1}$. VRT is a form of behavior therapy which relies on the process of systematic desensitization. For the patients who cannot imagine well enough, VRT serve as a mean to evoke stimuli which is similar to real world situations thus providing higher control over graded exposure stimulus parameters and thriftiness in delivering the equivalent as of vivo exposure therapy ${ }^{2},{ }^{3}$. It becomes an essential factor in VR psychotherapy treatment for the participant to submerse himself in the virtual environment. It is no distortion to state that the consequence of treatment relies on upon the total or aggregate submersion of the patient in the virtual world. For the effectiveness of the VR psychotherapy it becomes necessary that the participant shows similar physiological indications and fear symptoms that they go through the real world and experience the same increased rate of stimuli raising the fear and the corresponding anxiety level. Toexamine whether the participant experienced anxiety and fear, physiological data (i.e., blood pressure, pulse, and respiration) were measured simultaneously with the subjective unit of discomfort scale (SUDS) ${ }^{4}$.

\section{DISCUSSIONS}

\section{Acrophobia}

Derived from Greek words "acron" and "phobos", Acrophobia can be termed as extreme or irrational fear of heights and comes under the category of specific phobias called motion and space discomfort. People suffering from this particular phobia also experience heart palpitations, 
excessive sweating, nausea, and the inability to speak or think clearly resulting in behavior dysfunction that creates an interference with normal routine or interpersonal relationships.

Patients who enroll into this process of treatment are the people suffering and having acrophobia as their main accusation and who enrolled themselves for the treatment after public announcements on the national media, offering psychological treatment for acrophobia using VRET or exposure in vivo condition. To be included in the study, patients have to fulûl the DSM-IV criteria of acrophobia, showing acrophobia to be the main problem. After filtering the patients are asked to fill a set of questionnaires which depicts their present level of fear or anxiety towards height. The patients are then subjected to the VR environments by means of different software and hardware devices. Each VR session can last upto certain time limits depending on the patient's comfort level. During the sessions, the therapist keeps track of the patient's heart rate and anxiety level and communicate with the help of the microphone. The Exposure tends to be gradual and the therapist give verbal guidance and encouragement. If necessary, the therapist accompaniesor tries to encourage the patient or the participant but tries to withdraw his/her assistance as soon as possible. Patients were made to rate their anxiety level on regular times during the exposure therapy exercises on a 0-10 scale (SUDS) with 0 being the lowest and 10 being the highest. When the anxiety tends to diminish, the therapist made the patient to do a more difficult exercise. The sessions involved a number of different virtual environments specially created for the treatment such as (1) a public mall in Amsterdam (Magna Plaza) having

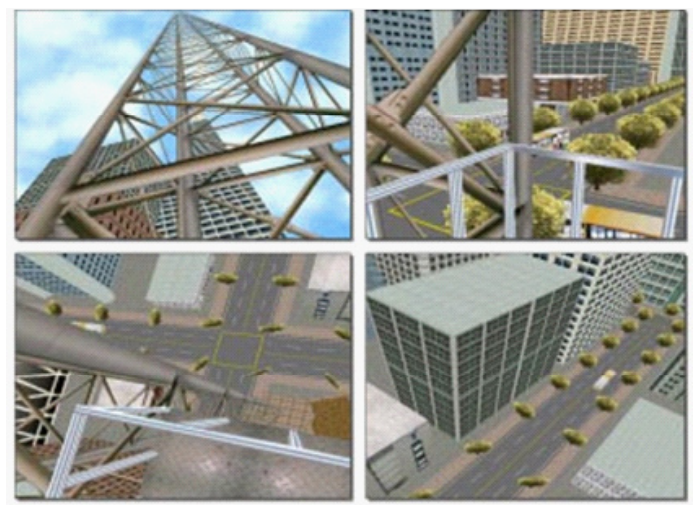

Fig. 2: A virtual scene of a bunge-jump tower ${ }^{26}$ four floors with balustrades and escalators; (2) a roof top garden at a university building (height:65 feet approx.) having a view of Magna Plaza and (3) a fire escape at Amsterdam (height:50 feet approx.). ${ }^{5}$. But subjecting the patients initially to the virtual environments and then experiencing them the exposure to vivo condition may cause the ceiling affect ${ }^{6}$. Thus, it becomes important to the therapist's point of view to evaluate the difference of values in the (SUD's) used during the therapy. In case of a vivo exposure the patient need to be subjected to the same virtual environment as designed in the VR treatment sessions. But research shows that difference between a virtual environment and an exposure in vivo condition shows almost identical values as compared to the level of exposure raising the sense the anxiety or fear ${ }^{5}$. Post session the patients are asked to fill in the questionnaires and a drop of values were noticed after the data were cumulatively analyzed for repeated measures.

\section{Claustrophobia}

Claustrophobia is typically the fear of confined spaces and can be as classified as an anxiety disorder which can result in panic attacks. Claustrophobia is functionally proportional to agoraphobia, but with more defined avoidance ${ }^{7,8,9}$ and also possess some similarity with the features of panic disorder. According to ${ }^{8}$ a participant suffering from claustrophobia shows the same bodily sensations as reported by a participant suffering from a panic disorder. Additionally, a participant suffering from claustrophobic fear is likely to show more phycological and cognitive symptoms than a participant with any other panic disorder. Claustrophobia provides several special characteristics that makes it suitable for its treatment with VR. With the focus on being immersed into the virtual environment the VRET elicit a significant proportion of anxiety in patients and enables them to surpass their fear with gradual exposure. The virtual reality environment is basically set up with a graphics workstation or any standalone application designed for this specific purpose and makes uses of a head mounted display with motion trackers attached to it. The virtual environment may consist of several stages or scenarios with different difficulty levels which the participants are subjected to depending upon their comfort level and confidence. The scenario may consist of a 
number of interconnected rooms where each room try to increase the level of claustrophobic fear for the participants. For instance, the first room might be normal, spacious and have adequate lighting whereas the last room might be small, windowless and dark $^{10}$. Some additional effects or animations can be added to the virtual environment such as closing the doors behind the user after the user passes through it, locking the doors of the room while progressing through it etc.

Before the participant is subjected to the virtual environment he/she is asked for an admissive semi structured interview which includes a series of screening questions that satisfies the criteria for anxiety disorders using DSM-IV diagnostic. After each of the sessions the participant might be asked to fill a set of questionnaires which provides a measure of the anxiety level faced by the participant during the therapy such as the SUDS which is a 10-point scale where 1 represents low anxiety and 10 represents high anxiety. Post Treatment there is a drop witnessed in the anxiety levels of the participants which is evaluated by going through the values of the questionnaires and calculating the mean score of these values. Also, the patients expressed more confidence in going through claustrophobic arousal situations such as using an elevator, going to theatres etc.

\section{Arachnophobia}

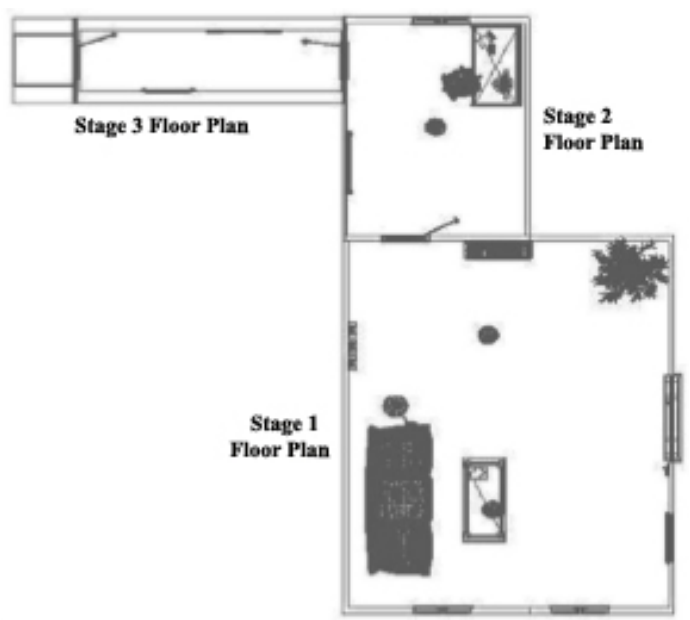

Fig. 3: A floor plan depicting changing size and features ${ }^{27}$
Arachnophbia or arachnephobia is a specific phobia which is characterized by fear of spiders and is derived from Greek words Arachne meaning "spider" and phobos meaning "phobia". An arachnophobic person tends to feel anxious or show signs of fear in any area that he/she believes could harbor spiders or upon the exposure to spiders. In addition to showing signs of anxiety and fear, participants also tend to hold the feeling of disgust because they might stimulate the feeling of disgust ${ }^{11}$ or they might be associated with the spreading the diseases. Under the circumstances of exposure to spiders the person tends to show panic, might experience problems in breathing or can show emotional outbursts. This behavior can hamper a person's interpersonal relationships, normal behavior or daily routines. Traditional treatment of arachnophobia includes systematic desensitization which involves exposure therapy or getting the individual to imagine situations. This exposure therapy can be implemented in vivo (using a live spider) or using a virtual reality environment.

VRET shows a greater advantage using other techniques as it equips the therapist with the freedom to control the feared stimuli and the movements of the virtual spider. In case of exposure in vivo it becomes difficult to have a control on the real spider and move the spider according to the requirements. Moreover, a virtual spider can be made to increase in size and can be made to appear more frightening to evoke the stimuli for the patients. In order to make the virtual therapy more effective the virtual spider must resemble closely to a real spider.In general, terms the greater the similarity between the virtual environment and the real environment, the more will be the transfer of training to the real world. To increase the level of presence on the behalf of the participant's side tactile augmentation can be introduced which involves the use of some position tracked real objects on the participant's behalf that provides a way to interact with the virtual world objects to suspend disbelief from the participant's perspective. Recent researches shows the use of a Novint Falcon device, a haptic interaction tool that can used within a dedicated virtual environment to elicit disgust, as changes in fear and in disgust were shown to be highly associated with the observed decline in arachnophobic symptoms ${ }^{12}$. A haptic 
interaction tool involves the transmission of signals between the participant and the computer via force, vibration and motion. This interaction also provides a feedback to the user as a force which points to a direction and possess certain magnitude. Using this haptic tool the participant or the user can interact with the virtual spider by means of his virtual hand within the virtual environment.

The treatment is generally done in several scenarios with each scenario more anxiety provoking or difficult than the preceding one. Each session of the treatment can last up to certain time limits or depending upon the comfort level of the participant. The participant is accompanied by a therapist who provides instructions over a microphone and can also involve a psychotherapist who encourages the participant during the treatment. The participants are not allowed to take any medication during the tenure of the therapy and are requested to fill in a set of questionnaires pre-and post the sessions. During the treatment, the participant might be asked to pick the spider with his/her virtual hand and place it in certain locations. This technique might be rise the anxiety level or elicit the feeling of disgust within the participant. After each session's, the participant is asked to fill questionnaire's which provide a measure for measuring the participant's current level of anxiety. Initially for the first few sessions a high value for anxiety was recorded but with the increasing number of sessions the anxiety value started to decrease which provides clear proof of reduction of dysfunctional behavior with the sessions. The participants tend to become more vigilant about the presence of spiders and don't show any precautionary measures relating to the avoidance of spiders and are able to live their life more relentlessly.

\section{Fear of Flying}

Fear of Flying has become a serious problem affecting considerable rate of population with personal and financial repercussions. According to survey nearly $25 \%$ of adults' have shown compelling level of anxiety when needed to fly; out of which $10 \%$ of them avoid such a situation ${ }^{13}$. Fear of flying holds most the people in comparison to the number of persons suffering from other related phobias. An individual suffering from the underlying phobia can go through several repercussions which include social embarrassment such as not being able to go to airport, boarding a flight, having tendency to lose control etc.

Hence it becomes an important problem to be to diagnosed and being able to be examined properly. Traditional methods include the vivo exposure therapy which has proved to be effective. However, the resources and time required to conduct such a therapy session have daunted many therapist and researchers. The group of Rothbaum and Hodges was one of the pioneers in considering fear of flying as an ideal candidate for virtual reality (VR) exposure therapy ${ }^{14}$. Virtual reality provided means to the researchers to create a virtual environment where the participant can have the sense of total immersion into the aero plane with additional cues of sound, vibration, touch etc. The main advantage of using the VRET therapy is the total cost that it saves while conducting the session. The session is carried under the guidance of therapist who consistently provide verbal cues to the participant. The therapist also has an control to the virtual environmentscene to bring in other aspects of boarding a flight such as altering weather conditions, flight take-off etc.

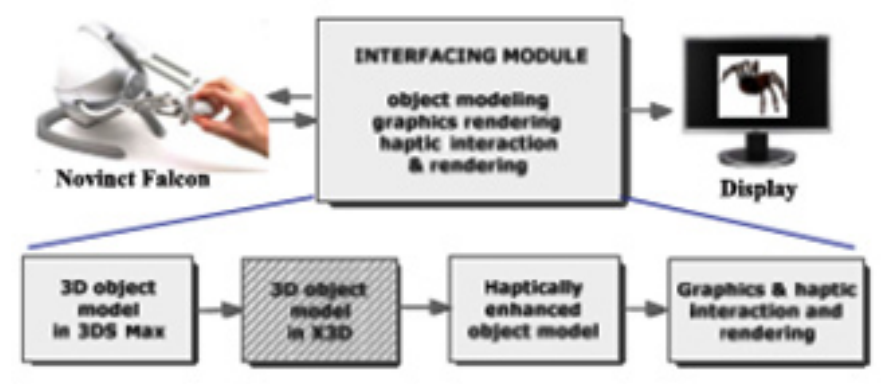

Fig. 4: An overview of Haptic system for using Novint Falcon ${ }^{28}$ 
The participant undergoing the therapy must meet DSM-IV ${ }^{15}$ criteria for specific phobia. The virtual scene can have different stages to increase the difficult level gradually. For example, the first scene can start from planning the trip where the participant is projected to room where he might be made to pack luggage and get ready for the trip, the second scene might have the airport scenario where the participant gets to hear the sound of the engines of a flight or can view a flight taking off, the third scene can have the participant in his seat and make the flight to take off. The patient is asked to answer specific questionnaire every 5 mins during the session which provides a track on the anxiety and fear level of the participant. After the session, the values obtained from the set of questionnaires are evaluated and a cumulative value is obtained which shows a decrease in the baseline anxiety and fear level of the participant. Following on the participant can board flights with a decrease in global impairment that cause problems in the participant's personal life.

\section{Assesment Methods For Anxiety Disorders}

The assessment of the different anxiety disorders can be done by means of following questionnaires:

\section{Questionnaire for the measuring of the sociodemographic data}

This questionnaire is generally used to evaluate the patient's sociodemographic data such as level of education, age, gender. It helps in understanding the patient present state in terms of technology also. For example, the use of $3 D$ movies or clips in the process of treatment is more compatible with a younger person using the VR control system in comparison to an older person having no or less experience in computer skills.

\section{The IGroup presence questionnaire}

IGroup Presence Questionnaire can be used within a virtual environment for the measurement of the sense of presence as experienced by the participant. This scale has been put up with two surveys conducted among 500 participants and contains many items. This scale is available in German, English and Dutch. This scale mainly focuses on the spatial presence, the level of involvement and the experience realized by the participant ${ }^{16}$.

\section{Anxiety Sensitivity Index (ASI)}

The Anxiety Sensitivity Index was originally written by Steven Reiss in 1983 and was used for the evaluation of Reiss's information processing model. ASI is basically used for the assessment of various dimensions of anxiety sensitivity. These dimensions include (1) physical symptoms of fear (2) public observation fear (3) cognitive fear symptoms ${ }^{17}$.

\section{The Body Sensation Questionnaire}

Usually used to determine the comfort level of the patient during the treatment. Includes field such as dizziness, blurred vision etc.Measured in 1 to 5 scale and contains approximately 20 questions.

\section{The Fear Questionnaire (FQ)}

The Fear Questionnaire (FQ) is an Englishlanguage questionnaire for self-assessment of anxiety symptoms and was under the title Fear Questionnaire (AF) translated into German. The English version is from Marks and Mathews from 1979. The German version is by Henry (2003) and Klaann, Hahlweg and Henry (2003). The questionnaire consists of several parts, in the first part, the respondent is asked to state what he is afraid, this question is missing in the German translation. in the second part follow 15 questions in which concrete situations are described and the respondent is on an eight-point scale specify how much he avoids these situations. the third part consists of five questions, what is the suffering Duck and impaired by anxious and depressive feelings and thoughts. the fourth part consists of a question how much the present fear of an eight-point scale is.

\section{Attitude towards height Questionnaire \\ Used to capture the behavior of participants or patients against gradual heights. And comprises of six questions providing an assessment for the attitude towards of height ${ }^{18}$. \\ Structured Clinical Interview for DSM-IV axis I disorders \\ This questionnaire is used for the diagnosis} of acrophobia within patients and is followed with a Symptom checklist to check for psychopathology. The paper comes in different versions with five as the latest version currently ${ }^{19}$. 


\section{H. The Acrophobia Questionnaire}

This questionnaire provides analysis of the anxiety scale (0-120 range) and avoidance scale $(0-60 \text { scale })^{20}$.

\section{The Behaviour Avoidance Test}

The Behaviour Avoidance Test (BAT) is commonly used as an analogue test situation to assess fears. Participants for studies using a BAT are typically selected by a screening self-report test of fear and, when given a BAT, are told the purpose of the situation is to measure fear.

\section{The Claustrophobia Questionnaire}

This questionnaire consists of several questions showing the traits of claustrophobia. For example: Standing in a closed elevator which is likely to have a power $\mathrm{cut}^{21}$.

\section{The Questionnaire on Attitudes towards Flying}

This questionnaire consist of 36 questions reflecting the traits of fear of flying and is pointed out on a 0 to 10 scale. It also provides assessment of the previous treatments as well as the history of fear of flying ${ }^{22}$.

\section{The Fear of Flying Inventory}

This questionnaire is used to measure the magnitude of fear of flying using a 0 to 8 scale having a 33-item list ${ }^{23}$.

\section{Fear of Spider Questionnaire}

The Fear of Spiders Questionnaire (FSQ), an 18-item self-report questionnaire assessing spider phobia, was developed in an attempt to complement the information provided by the Spider Phobia Questionnaire (SPQ) ${ }^{24}$.

\section{SUDS (Subjective Units of Discomfort Scale):}

This scale provides an indication to what degree a subject feel immersed in a physical or virtual environment and is generally measured in a 0 to 10 scale where 0 represents no anxiety and 10 represents extreme anxiety ${ }^{25}$.

\section{CONCLUSION}

Through this study, we have tried to show the efficacy of virtual reality in treating specific anxiety disorders. The VRET was successful in getting the participant habituated with the environment which was proved by the SUD's and the heart rate data as obtained by the results post therapy. Additionally, the results of the SUD's when compared with the results the of the vivo exposure showed the patients undergoing the same reactions. From the therapist's perspective, VRET provides the ease of creating such environment and delivering it effectively within multiple baseline with the patients. In addition to treating patients with anxiety disorders, VRET can likewise be used for the treatment of post-traumatic stress disorders by creating similar virtual environments with a control over the exposed stimuli. It has also been proved to be successful when used across the world for treatment during non-clinical circumstances such as war zone. Related studies indicate that with advancement of technology the virtual reality exposure surely to become popular with relatively cheap and will be available to ordinary practitioner in the coming few years.

\section{REFERENCES}

1. M. M. North, S. M. North, and J. R. Coble, Virtual Reality Therapy: IPI Press, 1996.

2. B. O. Rothabaum, L. F. Hodges, R. Kooper, D. Opdyke, J. S. Williford, and M. M. North, "The efficacy of virtual reality graded exposure in the treatment of acrophobia," Amer. J. Psych., 152, 626-628, 1995.

3. M. M. North and S. M. North, "Relative effectiveness of virtual environment desensitization and imaginal desensitization in the treatment of aerophobia," Arachnet Electr. J. Virtual Culture, 2, 1994.

4. Dong P. Jang, Jeong H. Ku, Young H. Choi, Brenda K. Wiederhold, San W. Nam, In Y. Kim, and Sun I. Kim, The Development of Virtual Reality Therapy (VRT) System for the Treatment of Acrophobia and Therapeutic Case

5. P.M.G. Emmelkamp a, ${ }^{*}$, M. Krijn a, A.M. Hulsbosch a, S. de Vries a, M.J. Schuemie 
b, C.A.P.G. van der Mast b, "Virtual reality treatment versus exposure in vivo: a comparative evaluation in acrophobia", Behaviour Research and Therapy 40 (2002) 509-516.

6. Paul M.G.Emmelkamp, Mary Bruynzeel, Leonie Dros, "Virtual Reality Treatment in Acrophobia: A Comparison with Exposure in Vivo" Cyberpsychology and Behavior University of Amsterdam, Delft University of Technology

7. D.H.Barlow (1988). "Anxiety and its disorders: The nature and treatment of anxiety and panic". The Guilford Press, New York:.

8. Booth, R., \& Rachman, S. (1992). "The reduction of claustrophobia-I."Behaviour Research and Therapy., 30,207-221.

9. Ost, L.G. (1987). "Age of onset in different phobias." Journal of Abnormal Psychology, 96, 223- 229.

10. Morgan Bruce \& Holger Regenbrecht."A Virtual Reality Claustrophobia Therapy System - Implementation and Test "Virtual Reality Conference, 2009.VR 2009. IEEE

11. G.C.L. Davey, "Psychopathology and treatment of specific phobias ", Psychiatry, 6(6) , 247-253, 2007.

12. Miroslav Cavrag, Guillaume Larivière, Ana-Maria Cretu "Interaction with Virtual Spiders for Eliciting Disgust in the Treatment of Phobias". 2014 IEEE International Symposium

13. T. S. Greco, "A cognitive-behavioural approach to fear of flying: A practitioner's guide," Phobia Practice Res. J., 2, 3-15, 1989.

14. B. O. Rothbaum, L. Hodges, B. A. Watson, G. D. Kessler, and D.Opdyke, "Virtual reality exposure therapy in the treatment of fear of flying: A case report," Behavior Res. Therapy, 34, 477-481,1996.

15. Diagnostic and Statistical Manual of Mental Disorders, 4th ed., Amer.Psych. Assoc., Washington, DC, 1994.

16. M. J. Schuemie, P. van der Straaten, M. Krijn, and C. A. van der Mast, "Research on Presence in Virtual Reality: A Survey," CyberPsychology \& Behavior, 4, (2), pp. 183-201, Apr. 2001. [Online]. Available: http://online.liebertpub.com/doi/ abs/10.1089/109493101300117884
17. Peterson, R.A., \& Reiss, S. (1992). Anxiety Sensitivity Index manual (2nd ed.). Worthington, $\mathrm{OH}$ : International Diagnostic Systems.

18. Abelson JL, \& Curtis GC. Cardiac and neuroendocrine responses to exposure therapy in height phobics: Desynchrony with the physiological response system. Behaviour Research \& Therapy; 27: 556561, 1989.

19. Firtst, M. B., Spitzer, R. L., Gibbon, M., \& Williams, J. B. W. (1996). Structured clinical interview for DSM-IV axis I disorders. Washington, DC: American Psychiatric Association.

20. Cohen DC. "Comparison of self-report and behavioral procedures for assessing acrophobia." Behavior Therapy; 8: 17-23, 1977.

21. Radomsky, A.S., Rachman, S., Thordarson, D.S., Mclsaac, H.K., Teachman, B.A. The Claustrophobia Questionnaire. Anxiety Disorders, 15, 287-297, 2001.

22. W.A. Howard, S.M. Murphy, and J.C. Clarke, "TheNature and Treatment of Fear of Flying: A Controlled Investigation,"Behavior Tnerapy, 14, pp. 557-567, 1983.

23. W. Scott, "A Fear of Flying Inventory," Innovations of Clin- ical Practice, P. Kellar and S. Hayman, eds., Professional Resource Exchange, Florida, 7,1987

24. Szymanski, J., \& O’Donohue, W. (1995). Fear of Spiders Questionnaire. Journal of Behavioral Therapy and Experimental Psychiatry, 26, 31-34.

25. Wolpe, J. (1969). The practice of behavior therapy. New York: Pergamon Press.

26. Dong P. Jang, Jeong H. Ku, Young H. Choi, Brenda K. Wiederhold, San W. Nam, In Y. Kim, and Sun I. Kim "The Development of Virtual Reality Therapy (VRT) System for the Treatment of Acrophobia and Therapeutic Case" 6, (3), 2002.

27. Morgan Bruce \& Holger Regenbrecht "A Virtual Reality Claustrophobia Therapy System - Implementation and Test “ University of Otago / New Zealand

28. Miroslav Cavrag, Guillaume Larivière, Stéphane Bouchard "Interaction with Virtual Spiders for Eliciting Disgust in the Treatment of Phobias". 